www.jmscr.igmpublication.org

Impact Factor 3.79

ISSN (e)-2347-176x

crossref DOI: http://dx.doi.org/10.18535/jmscr/v3i8.39

Journal Of Medical Science And Clinical Research

\title{
Epidermal Cyst Presenting As a Solitary Thyroid Nodule: A Rare Case Report
}

\author{
Authors \\ Dr. Dayanand D Choure ${ }^{1}$, Dr. Pramod D Nichat ${ }^{2}$, Dr. Samarth Agarwal ${ }^{3}$, \\ Dr. Mazhar Abbas Turabi ${ }^{4}$, Dr. Mukund B Tayade ${ }^{5}$ \\ ${ }^{1}$ Assistant Professor, ${ }^{2}$ Associate Professor, ${ }^{3,4}$ Senior Resident, ${ }^{5}$ Professor \\ Department of General Surgery, Grant Medical College and sir J J group of Hospitals, Mumbai \\ Email:drdayac@gmail.com ${ }^{1}$, nichatpramod@gmail.com ${ }^{2}$, rebellite@gmail.com ${ }^{3}$, \\ draco.mazhar@gmail.com ${ }^{4}$,drmukundtayade@yahoo.in ${ }^{5}$ \\ Corresponding Author \\ Dr. Dayanand D Choure
}

Assistant Professor, Dept of General Surgery, Grant Medical College and sir J J group of Hospitals, Mumbai Email:drdayac@gmail.com

\begin{abstract}
Thyroid Epidermal cysts are rare thyroid swellings with only a few cases reported in the literature so far. Thyroid epidermal cysts present like any other homologous thyroid swelling. These cysts are very rare and slow growing and classically present as a painless midline neck swellings. Most of the times, they are idiopathic in nature. We present a case of epidermal cyst presenting as anterior neck swelling and eventually managed by surgical intervention.
\end{abstract}

KEYWORDS: Thyroid; Epidermal cyst; Thyroid swelling.

\section{INTRODUCTION}

An epidermal cyst is a benign cyst usually found in the skin. The cyst develops from ectodermal tissue. Histologically, it is lined by a thin layer of squamous epithelium $^{1,2}$.

Several synonyms exist for epidermal cysts, including epidermoid cyst, epidermal inclusion cyst, infundibular cyst and keratin cyst $^{3,}, 4$. Epidermoid cysts commonly result from implantation of epidermis into the dermis, as in trauma or surgery. They can also be caused by a blocked pore adjacent to a body piercing. They are also seen in Gardner's syndrome on the head and neck $^{5}$. They may present as simple swelling or an inflamed swelling due to bacterial infection ${ }^{6}$.

However, very rarely as documented in literature, is the presence of an epidermal cyst presenting as a solitary thyroid nodule ${ }^{1,2}$. Although various theories have been suggested to explain etiology, its exact reason is still unclear. Thyroid gland's epidermal cyst is a rare tumour of this tissue. Because epidermal cysts are not common in mucosal sites such as thyroid; however, these can arise owing to squamous metaplasia of the glands ${ }^{7}$. 
The physical findings are classically a painless solitary thyroid nodule seen in front of the neck that moves with the deglutition. There are no palpable lymph nodes. There are no complaints of dyspnoea or dysphagia unless the swelling is very large. Our patient had solitary thyroid swelling which was eventually managed by surgical intervention.

\section{CASE REPORT}

A 46 year-old female patient presented with complain of swelling in neck since 6 months. The swelling was small initially which slowly increased in size to become a $3 \times 3 \mathrm{~cm}$ swelling. It was not associated with any aggravating or relieving factors. There was history of slight pain in swelling since 7 days without any history of fever. Also there was no history of dyspnoea, dysphagia or change in voice. On palpation the swelling was well-defined, non-tender and was cystic in consistency. The swelling was moving up with deglutition but not with the protrusion of tongue suggesting the swelling to be of thyroid in origin.

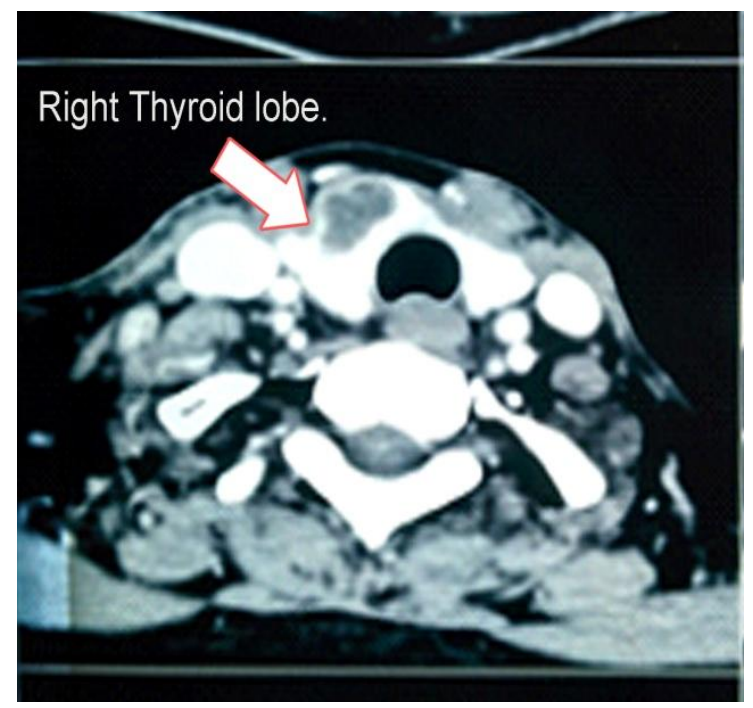

Fig. 1: Axial CT plate showing thyroid nodule
Patient was worked up at her first presentation at other hospital. Thyroid function test was done, patient was found to be euthyroid and anti-TPO antibodies were also in normal range. Ultrasound of the neck which was done thrice was suggestive of solitary thyroid swelling in the right lobe of $2 \times 3 \mathrm{~cm}$ size with features of colloid goiter. Fine needle aspiration cytology (FNAC) was done twice was suggestive of epidermal cyst.

When the patient presented to us, owing to discrepancy between USG and FNAC findings, a CT was done. On CT a well defined, unilocular, thin walled, peripherally enhancing cystic lesion was seen in right lobe of thyroid suggesting an intrathyroid lesion. A decision was taken to do right side hemi-thyroidectomy and the specimen was sent for histopathological examination. Patient recovered well with uneventful postoperative period.

On histopathological examination it was found to be Epidermal cyst surrounded by normal thyroid tissue.

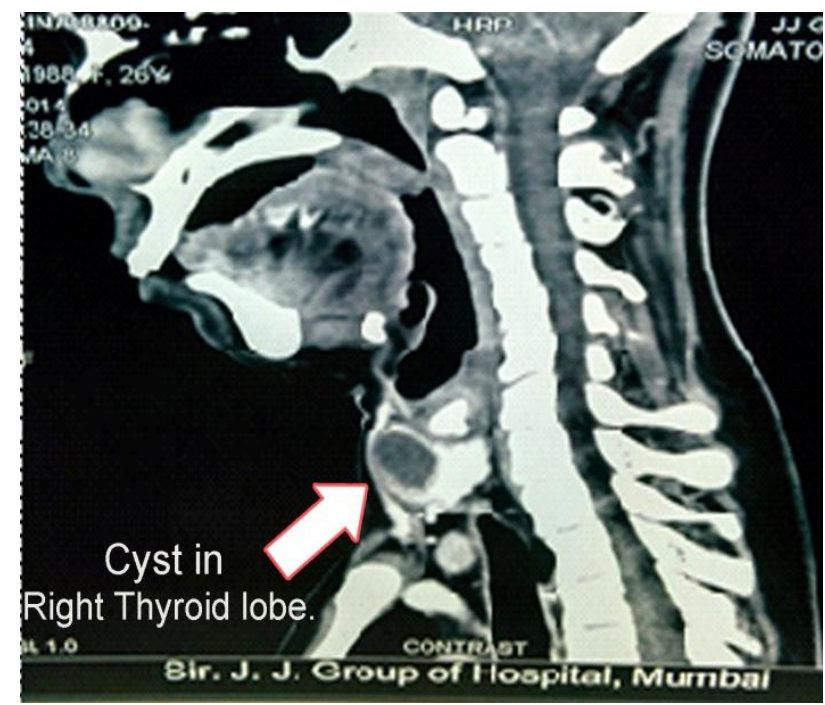

Fig. 2: Coronal CT plate showing the same nodule 


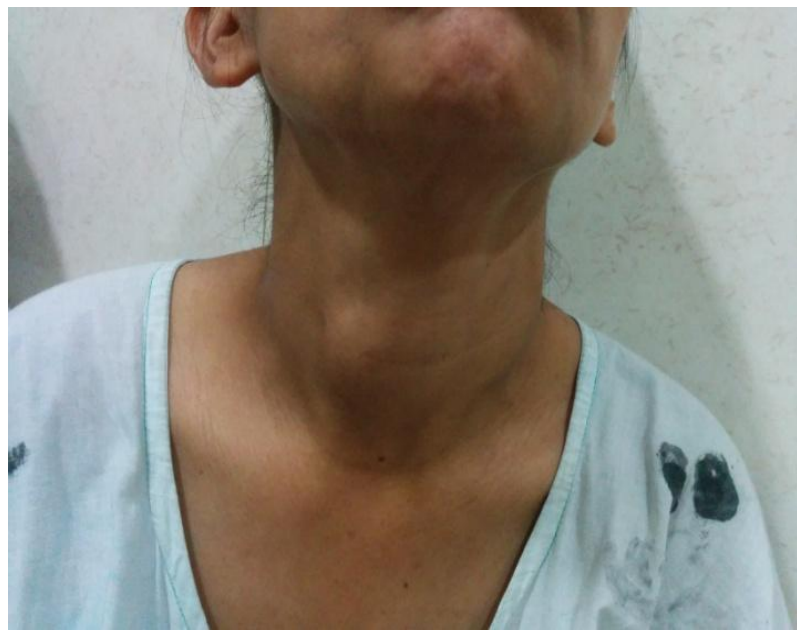

Fig. 3: Clinical photograph of thyroid swelling

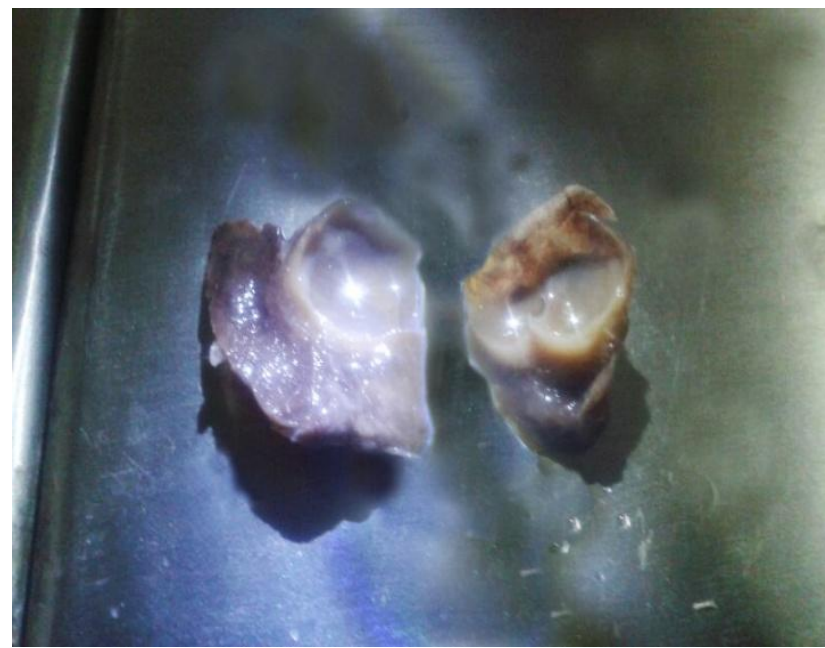

Fig. 5: Cut-section of the specimen showing presence of cyst.

\section{DISCUSSION}

In the present case the patient had multiple out patient department (OPD) visits with repeated investigations due to dilemma in finalizing the diagnosis. This is common as intra-thyroid epidermod cyst is quite rare.

Irrespective of the location the surgical treatment remains the same i.e. complete excision of epidermoid cyst along with the capsule. There is a $3 \%$ recurrence rate noted and reported, hence excision of the entire cyst wall is recommended ${ }^{5}$. For swellings over the other areas or those which are limited to skin and subcutaneous tissue, diagnosis of epidermoid cyst becomes quite easy.
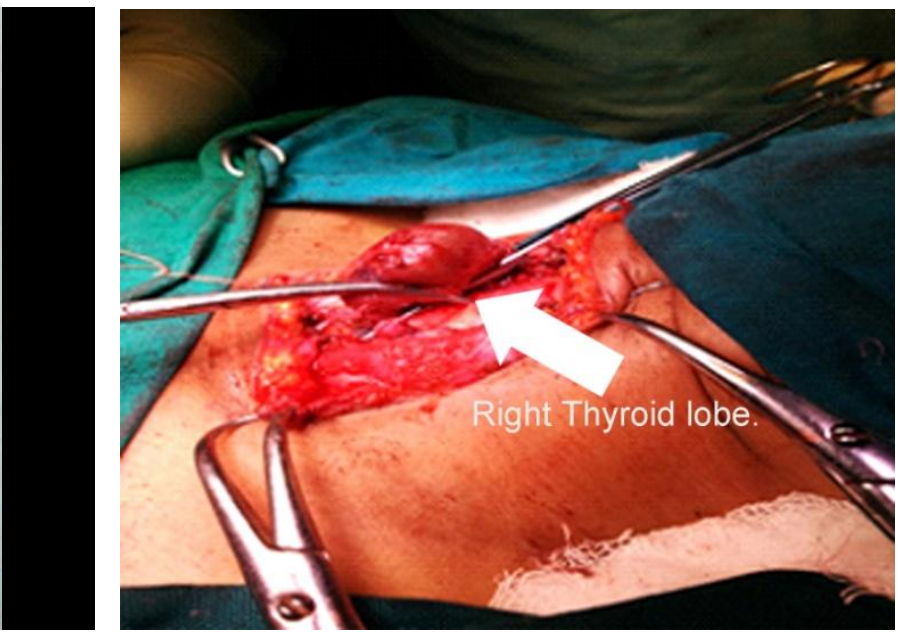

Fig, 4: Intra operative photograph of thyroid swelling

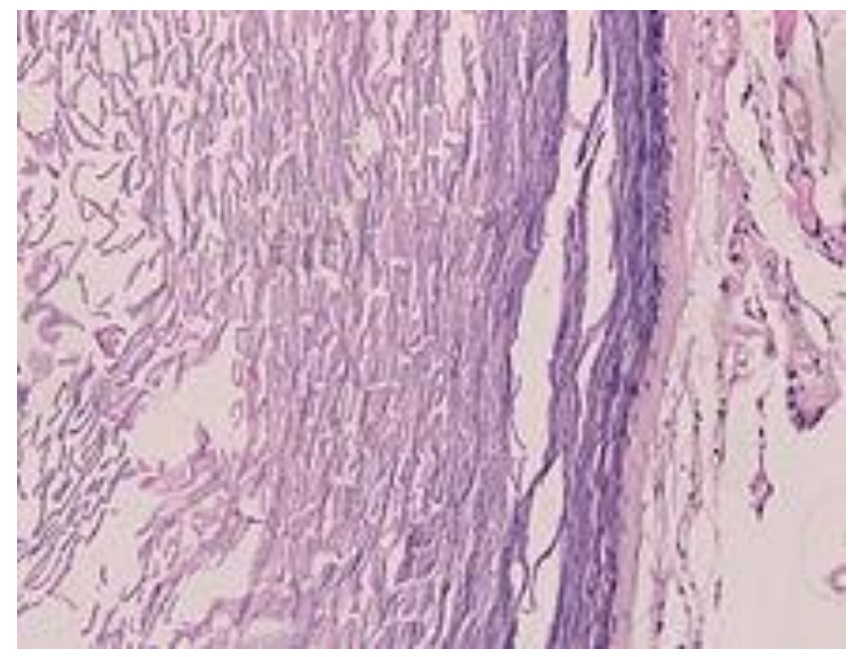

Fig 6: Histology showing epithelium and lamellated keratin (left side in the photo).

\section{CONCLUSION}

The epidermal cysts are common over the skin of back, chest and genitalia. Though they are extremely rare inside the thyroid gland, we would like to stress that they should be kept in mind while dealing with a thyroid swelling as a rare presentation, as it may avoid the diagnostic dilemma and decrease the load of unnecessary repetition of investigations.

\section{REFERENCES}

1. Chen, K. T. K. Fine-needle aspiration cytology of epidermoid cyst of the thyroid: Report of a case and review of seven cases. Diagn. Cytopathol. 2007;35:123-4. 
2. Rumberger LK, Mancini M, Curzon M, Orucevic A; Intrathyroidal epidermoid cyst associated with nodular Hashimoto's thyroiditis: a rare pathologic finding in a common clinical entity; Am Surg. 2014;80:205-6

3. Freedberg, et al. Fitzpatrick's Dermatology in General Medicine. (6th ed.). McGrawHill.

4. James, William; Berger, Timothy; Elston, Dirk. Andrews' Diseases of the Skin: Clinical Dermatology. (10th ed.). Saunders.

5. KA Pandya, F Radke. Benign skin lesions: Lipomas, epidermal inclusion cysts, muscle and nerve biopsies. SurgClin North Am. 2009;89:677-87.

6. Linda J Fromm, Nathalie C Zeitouni, Julie C Harper, David F Butler, Christen M Mowad, Catherine M Quirk, Epidermal inclusion cyst, http://emedicine.medscape.com/article/106 1582-clinical

7. Yilmaz M, Haciyev $\mathrm{Y}$, Mamanov M, Cansiz H, Yilmaz R. Epidermal inclusion cyst of the larynx. J Craniofac Surg 2011; 22: $1-2$. 